Hope College

Hope College Digital Commons

Faculty Publications

10-10-2013

\title{
Day-night Differences in Neural Activation in Histaminergic and Serotonergic Areas with Putative Projections to the Cerebrospinal Fluid in a Diurnal Brain
}

\author{
Alexandra Castillo-Ruiz \\ Michigan State University \\ Andrew J. Gall \\ Michigan State University, gall@hope.edu \\ Laura Smale \\ Michigan State University \\ Antonio A. Nunez \\ Michigan State University
}

Follow this and additional works at: https://digitalcommons.hope.edu/faculty_publications

Part of the Behavioral Neurobiology Commons, and the Biological Psychology Commons

\section{Recommended Citation}

Repository citation: Castillo-Ruiz, Alexandra; Gall, Andrew J.; Smale, Laura; and Nunez, Antonio A., "Daynight Differences in Neural Activation in Histaminergic and Serotonergic Areas with Putative Projections to the Cerebrospinal Fluid in a Diurnal Brain" (2013). Faculty Publications. Paper 1500.

https://digitalcommons.hope.edu/faculty_publications/1500

Published in: Neuroscience, Volume 250, October 10, 2013, pages 352-363. Copyright @ 2013 Elsevier.

This Article is brought to you for free and open access by Hope College Digital Commons. It has been accepted for inclusion in Faculty Publications by an authorized administrator of Hope College Digital Commons. For more information, please contact digitalcommons@hope.edu. 


\title{
Day-night differences in neural activation in histaminergic and serotonergic areas with putative projections to the cerebrospinal fluid in a diurnal brain
}

\author{
Alexandra Castillo-Ruiz ${ }^{a, b, 1,{ }^{*}, \text { Andrew J. Galla }{ }^{a} \text { Laura Smale }}{ }^{a, b}$, and Antonio A. Nunez ${ }^{a, b}$ \\ aDepartment of Psychology, Michigan State University, East Lansing, MI 48824, USA \\ becology, Evolutionary Biology, and Behavior Program, Michigan State University, East Lansing, \\ MI 48824, USA
}

\begin{abstract}
In nocturnal rodents, brain areas that promote wakefulness have a circadian pattern of neural activation that mirrors the sleep/wake cycle, with more neural activation during the active phase than during the rest phase. To investigate whether differences in temporal patterns of neural activity in wake-promoting regions contribute to differences in daily patterns of wakefulness between nocturnal and diurnal species, we assessed Fos expression patterns in the tuberomammillary (TMM), supramammillary (SUM), and raphe nuclei of male grass rats maintained in a 12:12h light-dark cycle. Day-night profiles of Fos expression were observed in the ventral and dorsal TMM, in the SUM, and in specific subpopulations of the raphe, including serotonergic cells, with higher Fos expression during the day than during the night. Next, to explore whether the cerebrospinal fluid is an avenue used by the TMM and raphe in the regulation of target areas, we injected the retrograde tracer cholera toxin subunit beta (CTB) into the ventricular system of male grass rats. While CTB labeling was scarce in the TMM and other hypothalamic areas including the suprachiasmatic nucleus, which contains the main circadian pacemaker, a dense cluster of CTB-positive neurons was evident in the caudal dorsal raphe, and the majority of these neurons appeared to be serotonergic. Since these findings are in agreement with reports for nocturnal rodents, our results suggest that the evolution of diurnality did not involve a change in the overall distribution of neuronal connections between systems that support wakefulness and their target areas, but produced a complete temporal reversal in the functioning of those systems.
\end{abstract}

\section{Keywords}

Fos; serotonin; histamine; cerebrospinal fluid; circadian; grass rat

(C) 2013 IBRO. Published by Elsevier Ltd. All rights reserved.

"Corresponding author: Alexandra Castillo-Ruiz, 55 Lake Avenue North, University of Massachusetts Medical School, Worcester, MA 01655, USA, Tel: + 1517353 9066, Fax: + 1508856 6778, Alexandra.Castillo-Ruiz@umassmed.edu.

${ }^{1}$ Present address: Department of Neurology, University of Massachusetts Medical School, Worcester, MA 01655, USA

The authors state no conflict of interest.

Author contributions: A.C.R. designed and performed experiments, analyzed data and wrote the manuscript; A.J.G. designed and performed experiments; L.S. and A.A.N. designed experiments and wrote the manuscript. All authors discussed the results and implications and commented on the manuscript at all stages.

Publisher's Disclaimer: This is a PDF file of an unedited manuscript that has been accepted for publication. As a service to our customers we are providing this early version of the manuscript. The manuscript will undergo copyediting, typesetting, and review of the resulting proof before it is published in its final citable form. Please note that during the production process errors may be discovered which could affect the content, and all legal disclaimers that apply to the journal pertain. 


\section{Introduction}

Wakefulness is supported by several systems distributed throughout the mammalian brain, including the serotonergic raphe and the histaminergic tuberomammillary nuclei (TMM; reviewed in Jones, 2005). In nocturnal rodents these brain areas exhibit increased activation during the active phase in comparison to the inactive phase of the animals' activity/rest cycle (Guzman-Marin et al., 2000, Ko et al., 2003, Takahashi et al., 2006). Likewise, in the diurnal grass rat, Arvicanthis niloticus, the ventral tuberomammillary nucleus (VTM) exhibits a day-night difference in neural activation (as assessed by Fos expression) that resembles the species daily activity/rest cycle (Novak et al., 2000), but that pattern has not been documented for this rodent's dorsal tuberomammillary nucleus (DTM). Also, it remains to be determined whether the raphe nuclei of diurnal species exhibit daily patterns of neural activation and whether the phase of such rhythms differs between diurnal and nocturnal animals. The implications of these observations are important for understanding the differential roles that histaminergic and serotonergic brain areas have on the circadian regulation of behavior in diurnal and nocturnal species.

Given that neural activity in histaminergic and serotonergic areas appears to be regulated by circadian mechanisms, and that in other arousal systems increased neural activity is accompanied by release of neurotransmitters at terminal buttons (Greco et al., 1999, Greco et al., 2000), it is likely that the release of histamine (HA) and serotonin (5HT) into target areas also follows a circadian pattern. Of particular interest is the choroid plexus (CP) as a possible target for circadian modulation by histaminergic and/or serotonergic inputs. The $\mathrm{CP}$, located at different sites of the third $(3 \mathrm{~V})$, fourth $(4 \mathrm{~V})$ and lateral ventricles (LV; Wolburg and Paulus, 2010), is the site of production of the cerebrospinal fluid (CSF), which transports essential molecules throughout the nervous system. The $\mathrm{CP}$ contains receptors for 5HT (Watson et al., 1995) and HA (Crook et al., 1986), and both neurotransmitters influence metabolism in this area (Crook et al., 1984, Watson et al., 1995); the route may be through their direct release into the CSF as suggested by studies that report the presence of histaminergic (Ericson et al., 1987, Tillet et al., 1998) and serotonergic (Lorez and Richards, 1973, Chan-Palay, 1976) axons or dendrites in close proximity to the ventricles.

Here we examine the hypothesis that differences in temporal patterns of neural activity in histaminergic and serotonergic areas could contribute to differences in daily patterns of arousal between nocturnal and diurnal species. To this end, we used Fos expression to examine functional changes in cells of the DTM, VTM, and dorsal (DR) and median (MR) raphe nuclei of male grass rats across the $24 \mathrm{~h}$ day. All of these regions not only support wakefulness, but also have been implicated in the modulation of circadian entrainment (Meyer-Bernstein and Morin, 1999, Harrington et al., 2000). We also measured Fos expression in the supramammillary nucleus (SUM) because of its role in arousal and reward (reviewed in Pan and McNaughton, 2004, Ikemoto, 2010). Additionally, to examine whether serotonergic and histaminergic areas of the grass rat brain have access to the CSF, we injected the retrograde tracer cholera toxin subunit beta (CTB) into the $3 \mathrm{~V}$ or $\mathrm{LV}$ and examined the pertinent areas for the presence of CTB labeled neurons. In the DR we combined the analysis of CTB with identification of 5HT-positive neurons.

\section{Experimental procedures}

Adult male grass rats, born in our laboratory and derived from a group brought from Kenya (Katona and Smale, 1997), were used in this study. Animals were kept on a 12:12h lightdark cycle [lights on at zeitgeber time (ZT) 0] and provided with ad libitum access to water and food. All experiments were approved by the Michigan State University Institutional Animal Care and Use Committee in compliance with guidelines established by that 
institution as well as the National Institutes of Health Guide for the Care and Use of Laboratory Animals.

\subsection{Experiment 1: Neural activation in TMM, SUM and raphe}

2.1.1. Immunocytochemistry (ICC)—Animals ( $\mathrm{n}=6$ per ZT) were perfused at ZTs 2 , $6,10,14,18$, and 22. Intraperitoneal injections of sodium pentobarbital (Ovation Pharmaceutical, Deerfield, IL, USA) were used to deeply anesthetize the animals. To prevent exposure to light, animals that were perfused during the dark phase were injected under a red light ( $<5$ lux $)$ and were fit with an aluminum foil hood upon anesthesia onset. All animals were intracardially perfused with $0.9 \%$ saline, followed by $4 \% \mathrm{~N}-(3-$ Dimethylaminopropyl)-N'-ethylcarbodiimide hydrochloride (Sigma-Aldrich, St. Louis, MO, USA) in $0.1 \mathrm{M}$ phosphate buffer (PB; note that this step was called for by the HA antibody used, AB5885; Millipore, Temecula, CA, USA), and then by 4\% paraformaldehyde with 75 $\mathrm{mM}$ lysine and $10 \mathrm{mM}$ sodium periodate (PLP) in $0.1 \mathrm{M}$ PB. Following perfusion, brains were removed, post-fixed for approximately $4 \mathrm{~h}$ in PLP, and transferred to $20 \%$ sucrose in $0.1 \mathrm{M} \mathrm{PB}$ at $4^{\circ} \mathrm{C}$ until they sunk to the base of the vial. Then, coronal sections $(30 \mu \mathrm{m})$ were cut on a freezing sliding microtome. Alternate sections were collected in three series in cryoprotectant and stored at $-20^{\circ} \mathrm{C}$ until further processing. One series was used for the colocalization of Fos and 5HT and another for Fos and HA.

Since the ICC for Fos and HA did not produce adequate double labeling (data not shown), we limited our study to the analysis of Fos expression in the TMM and SUM and of Fos and 5HT expression in the raphe. Unless indicated otherwise, all ICC procedures were carried out at room temperature, and all incubations and rinses involved gentle agitation. In addition, with the exception of experiment 2 , sections were rinsed 3 times ( $5 \mathrm{~min} / \mathrm{rinse})$ in $0.01 \mathrm{M}$ phosphate buffered saline (PBS) between all ICC steps and all incubations included $0.3 \%$ Triton X-100 (TX) and PBS. For Fos staining, free-floating sections containing the TMM, SUM, and raphe were washed in PBS (6 times, 10min/rinse), blocked (1 h) using 5\% normal donkey serum (NDS; 017-000-121; Jackson ImmunoResearch Laboratories, West Grove, PA, USA), and incubated overnight in a rabbit anti-Fos antibody (1:20000 in 3\% NDS; SC-52; Santa Cruz Biotechnology, Santa Cruz, CA, USA) at $4^{\circ} \mathrm{C}$. Then, sections were treated with a donkey anti-rabbit biotinylated antibody (1:200 in 3\% NDS for $1 \mathrm{~h}$; 711-065-152; Jackson ImmunoResearch Laboratories) and the avidin-biotin peroxidase method (0.9\% each avidin and biotin solutions for $1 \mathrm{~h}$; PK-6100; Vector Laboratories, Burlingame, CA, USA) with $0.025 \%$ diaminobenzidine enhanced with $2.5 \%$ nickel sulfate as the chromogen. For 5HT staining, the same sections were blocked $(1 \mathrm{~h})$ in 5\% normal goat serum (NGS; S-1000; Vector Laboratories), incubated overnight in a rabbit anti-5HT antibody (1:10000 in 3\% NGS; NT-102; Protos Biotech Corp., New York, NY, USA) at $4^{\circ} \mathrm{C}$ and treated with a goat anti-rabbit biotinylated antibody (1:200 in 3\% NGS for $1 \mathrm{~h}$; BA-1000; Vector Laboratories), after which the avidin-biotin peroxidase method ( $0.9 \%$ each avidin and biotin solutions for $1 \mathrm{~h}$ ) was used with $0.02 \%$ diaminobenzidine as the chromogen. All sections were mounted on slides, dehydrated, and coverslipped with DPX mountant for histology (Sigma-Aldrich).

2.1.2. Quantification-For Fos quantification in the TMM, we selected one section that contained both the VTM and DTM. For the quantification of Fos and 5HT expression in the raphe, we selected three sections containing the medial subdivision of the dorsal raphe (mDR), one containing the lateral subdivision of this nucleus (IDR), and one of the MR. In addition, we quantified the expression of Fos in one section containing the SUM.

For the DTM, cells expressing Fos were counted within a region defined by a $120 \mu \mathrm{m}^{2}$ box placed on either side of the $3 \mathrm{~V}$; whereas for the VTM, we used a $150 \mu \mathrm{m}^{2}$ box placed at the 
edge of the brain following the criteria used previously by our group (Novak et al., 2000). For the IDR, the sampling region was defined by a $150 \mu \mathrm{m}$ (width) $\times 650 \mu \mathrm{m}$ (height) box placed lateral to the mDR, immediately dorsal to the medial longitudinal fasciculus (Fig. 1A). For the mDR, the three sections analyzed corresponded to levels 3, 4, and 5 following the nomenclature of Janusonis and colleagues (Janusonis et al., 1999), which in here we refer to as mDR3, mDR4, and mDR5, respectively. Levels 1 and 2 were not analyzed because Fos staining was rare in those regions (data not shown). The sampling boxes used for $\mathrm{mDR} 3$ and $\mathrm{mDR} 4$ [150 $\mu \mathrm{m}$ (width) $\times 650 \mu \mathrm{m}$ (height)] were placed at the midline, medial to the dorsal borders of the medial longitudinal fasciculi (Fig. 1A and 1C). The sampling box for mDR5 $\left(160 \mu \mathrm{m}^{2}\right)$ was placed ventral to the $4 \mathrm{~V}$ (Fig. 1E). For the MR, the sampling region was defined by a box [(150 $\mu \mathrm{m}$ (width) $\times 700 \mu \mathrm{m}$ (height) $]$ placed on midline in an area rich in 5HT staining (Fig. 1A). Finally, a $160 \mu \mathrm{m}^{2}$ sampling box was placed in the caudal SUM, as described previously (Castillo-Ruiz et al., 2010).

Counts were done bilaterally in the DTM, VTM, and IDR, and cell numbers for these areas were averaged for each section. The $\mathrm{mDR}, \mathrm{MR}$, and SUM did not require this procedure since these regions extended across the midline (see Fig. 1 and Castillo-Ruiz et al., 2010). In addition, for the IDR and all levels of the mDR cell counts were divided by the area occupied by their sampling box and the results are expressed as number of cells $/ \mathrm{mm}^{2}$. This procedure was necessary because for some sections part of the sampling boxes fell outside the target areas. All counts were done using a $25 \times$ objective under a light microscope equipped with a drawing tube (Laborlux 8, Leitz Wetzlar GBH, Wetzlar, Germany), and performed by an investigator blind to the time of day at which the tissue was collected.

Data were analyzed with non-parametric methods, because of unequal variance.

Specifically, we used Kruskal-Wallis tests to assess the effects of sampling time on the expression of Fos in serotonergic and non-serotonergic cells. Significant effects of sampling time were followed by Mann-Whitney $U$ tests. For all comparisons differences were considered significant when $\mathrm{p}$ was less than 0.05 (two-tailed tests). The software used for the statistical analyses was SPSS 17 (SPSS Inc., Chicago, IL, USA).

\subsection{Experiment 2: Putative projections to the CSF}

2.2.1. Surgical procedures-Grass rats were deeply anesthetized with isoflurane and their heads were shaved, disinfected with povidone-iodine, and injected with lidocaine (6 $\mathrm{mg} / \mathrm{kg}$; s.c.; Hospira Inc., Lake Forest, Il, USA) and buprenorphine $(0.05 \mathrm{mg} / \mathrm{kg}$; s.c.;

PharmaForce, Inc., Hiliard, OH, USA). Then, animals were placed in a stereotaxic apparatus (Stoelting Co., Wood Dale, Il, USA) with the incisor bar placed $6 \mathrm{~mm}$ below the center of the ear bars for injections to the $3 \mathrm{~V}$ and $4.5 \mathrm{~mm}$ below the center for injections to the LV. A hamilton syringe (Hamilton Company, Reno, NV, USA), filled with CTB (10 mg/ml; 3V: 20 nanoliters, LV: 40 nanoliters; C9903; Sigma-Aldrich) was used to deliver the tracer. The syringe was angled at 10 degrees for injections to the $3 \mathrm{~V}$ and at 0 degrees for injections to the LV. The coordinates to determine the injection site for the $3 \mathrm{~V}$ were: $\mathrm{AP}(+1.4 \mathrm{~mm}), \mathrm{ML}$ (+ $1.3 \mathrm{~mm}$, right), DV (- $6.2 \mathrm{~mm})$, and for the $\mathrm{LV}: \mathrm{AP}(+1.8 \mathrm{~mm}), \mathrm{ML}(+0.5 \mathrm{~mm}$, right), DV (- $2.5 \mathrm{~mm})$; the coordinates were determined with reference to bregma (AP and ML) and dura (DV). The tracer was delivered over a $5 \mathrm{~min}$ interval and left in place for $5 \mathrm{~min}$ (LV injections) or $15 \mathrm{~min}$ ( $3 \mathrm{~V}$ injections). The incision was closed with autoclips, and treated with novalsan antiseptic ointment (Fort Dodge Animal Health, Fort Dodge, IA, USA). To prevent dehydration, all animals received $2 \mathrm{cc}$ of sterile saline (s.c.). The animals were left to recover on a heating pad, and received post-operatively either buprenorphine $(0.05 \mathrm{mg} /$ $\mathrm{kg}$; s.c.; every $12 \mathrm{~h}$ for the first day) and ketoprofen $(5 \mathrm{mg} / \mathrm{kg}$; s.c.; every $24 \mathrm{~h}$ for the following two days; Fort Dodge Animal Health), or ketoprofen ( $5 \mathrm{mg} / \mathrm{kg}$; s.c.; at the time of 
surgery) and meloxicam ( $0.2 \mathrm{mg} / \mathrm{kg}$; orally; every $24 \mathrm{~h}$ for the following two days; Boehringer Ingelheim Vetmedica, Inc., St. Joseph, MO, USA).

2.2.2. Distribution of retrogradelly labeled cells-Seven days after CTB injections (Mikkelsen et al., 1997), animals were given an overdose of sodium pentobarbital and perfused transcardially during the light phase (between ZTs 2-7) with PBS, followed by PLP. Brains were then post-fixed and sectioned following the procedure described above. For injections to the $3 \mathrm{~V}$, the tissue was rinsed ( 6 times, $10 \mathrm{~min} /$ rinse) in $0.05 \mathrm{M}$ tris-buffered saline (TBS) in $0.04 \%$ TX, blocked (30 min) in 5\% normal rabbit serum (S-5000; Vector Laboratories) in $0.04 \%$ TX-TBS, and rinsed once in $0.04 \%$ TX-TBS. Then, sections were incubated in a goat anti-CTB antibody (1:5000 in 0.04\% TX-TBS; 703; List Biological Laboratories, Inc., Campbell, CA, USA) for $60 \mathrm{~h}$ at $4^{\circ} \mathrm{C}$. After this step, the tissue was rinsed in $0.02 \%$ TX-TBS (5 min/rinse) and incubated in a rabbit anti-goat antibody (1:200 in $0.02 \%$ TX-TBS for $2 \mathrm{~h}$; BA-5000; Vector Laboratories). Then, sections were rinsed in $0.02 \%$ TX-TBS ( 3 times, $5 \mathrm{~min} /$ rinse) and incubated in avidin-biotin peroxidase complex ( $0.9 \%$ each avidin and biotin solutions in $0.02 \%$ TX-TBS for $2 \mathrm{~h}$ ). After 3 rinses $(5 \mathrm{~min} /$ rinse) in $0.02 \%$ TX-TBS and one rinse (5 $\mathrm{min}$ ) in TBS, the tissue was reacted in $0.01 \%$ diaminobenzidine in $0.1 \mathrm{M} \mathrm{PB}$ and then rinsed in $0.1 \mathrm{M}$ Tris buffer (4 times, $5 \mathrm{~min} /$ rinse). For injections to the LV, the tissue was rinsed in PBS (6 times, $5 \mathrm{~min} / \mathrm{rinse}$ ) and then incubated in 10\% hydrogen peroxide in PBS for 20 min. After this step, we followed the cytoplasmic staining protocol outlined above (section 2.1.1, for 5HT) using normal horse serum (S-2000; Vector Laboratories), goat anti-CTB antibody (1:100000), and biotinylated horse anti-goat as secondary antibody (1:200; BA-9500; Vector Laboratories). All sections were mounted on slides, then dehydrated, coverslipped with DPX, and later examined using a light microscope (Laborlux 8, Leitz Wetzlar GBH, Wetzlar, Germany and DM IRB Leica Microsystems, Deerfield, IL, USA).

2.2.3. Distribution of cells labeled for CTB and $5 \mathrm{HT}$-Since CTB cells were absent in the VTM and rare in the DTM (see section 3.2.1), we limited our double-labeling analysis to $\mathrm{CTB}$ and $5 \mathrm{HT}$ in $\mathrm{mDR} 3$ through $\mathrm{mDR} 5$, which were the only regions of the $\mathrm{mDR}$ containing CTB-positive cells. Free-floating sections containing mDR3, mDR4, and mDR5 were blocked (30 min) in 5\% NDS (Jackson ImmunoResearch Laboratories), after which they were incubated in a rabbit anti-5HT antibody $\left(1: 1000\right.$; Protos Biotech) for $48 \mathrm{~h}$ at $4{ }^{\circ} \mathrm{C}$, and treated with a Cy2 donkey anti-rabbit antibody (1:100 for $2 \mathrm{~h}$; 711-225-152; Jackson ImmunoResearch). Then, the tissue was incubated in a goat anti-CTB antibody (1:500; List Biological Laboratories) for $48 \mathrm{~h}$ at $4^{\circ} \mathrm{C}$ and then treated with a $\mathrm{Cy} 3$ donkey anti-goat antibody (1:100 for $2 \mathrm{~h}$; 705-165-147; Jackson ImmunoResearch Laboratories). Between steps, sections were rinsed several times in PBS with $0.1 \% \mathrm{TX}$, and all incubations included PBS and $0.3 \%$ TX. Sections were mounted on slides, dehydrated, coverslipped with DPX, and stored at $4{ }^{\circ} \mathrm{C}$. To examine colocalization of CTB and 5HT we used a fluorescent microscope (Zeiss Axioscop 2 plus, Carl Zeiss, Göttingen, Germany) equipped with green and red filters. Photomicrographs were taken at 40-100 $\times$ magnification. For confirmation of colocalization of CTB and 5HT, we combined red and green color channels using Adobe Photoshop (Adobe Systems, San Jose, CA, USA). The number of cells labeled for 5HT and/ or CTB were counted for the whole DR per section. Here, we report the average of those counts for all levels of the mDR combined.

\section{Results}

\subsection{Experiment 1: Neural activation in TMM, SUM and raphe}

In the raphe nuclei, the total number of 5HT-positive cells did not differ significantly as a function of time of day in any region (all $\mathrm{p}$ values $>0.21$ ). Data on serotonergic cells 
expressing Fos in the 1DR, and mDR3 were not analyzed because double-labeled cells were extremely rare in those regions at all times of day. In these two regions, Fos expression in non-serotonergic cells was also not significantly affected by ZT (IDR: $X^{2}=9.93, \mathrm{df}=5, \mathrm{p}=$ 0.08 ; and mDR3: $\mathrm{X}^{2}=8.17, \mathrm{df}=5, \mathrm{p}=0.15$ ).

In the mDR4, day-night differences in Fos expression were evident in serotonergic cells ( $\mathrm{X}^{2}$ $=16.45, \mathrm{df}=5, \mathrm{p}<0.01 ;$ Fig. $2 \mathrm{~A})$ as well as in non-serotonergic cells $\left(\mathrm{X}^{2}=20.61, \mathrm{df}=5, \mathrm{p}\right.$ $<0.01$; Fig. 2B). Pair-wise comparisons revealed similar patterns of Fos expression in serotonergic and non-serotonergic cells, with the lowest levels occurring between ZT 18 and ZT 22 (Fig. 2A and 2B). In contrast to the mDR4, in the mDR5 a significant day-night difference in Fos expression was seen only in serotonergic cells $\left(\mathrm{X}^{2}=15.25, \mathrm{df}=5, \mathrm{p}<\right.$ 0.01; Fig. 2C and 3), but not in non-serotonergic cells $\left(\mathrm{X}^{2}=10.29\right.$, $\mathrm{df}=5, \mathrm{p}=0.07$; Fig. $2 \mathrm{D}$ and 3). The pattern of Fos expression observed in serotonergic cells of the mDR5 was similar to that seen in the mDR4, with the lowest levels of Fos expression seen between ZT 18 and ZT 22 (Fig. 2C and 3). Finally, in the MR serotonergic cells did not show a day-night differences in Fos expression $\left(\mathrm{X}^{2}=9.01, \mathrm{df}=5, \mathrm{p}=0.11\right.$; Fig. 2E), but non-serotonergic cells $\operatorname{did}\left(\mathrm{X}^{2}=13.32, \mathrm{df}=5, \mathrm{p}=0.02 ;\right.$ Fig. $\left.2 \mathrm{~F}\right)$, with the lowest levels occurring at ZT 18 and ZT 22 (Fig. 2F).

In the VTM, DTM, and SUM there was a significant effect of time on the expression of Fos $\left(X^{2}=15.56, d f=5, p<0.01 ; X^{2}=19.46, d f=5, p<0.01 ;\right.$ and $X^{2}=19.77, d f=5, p<0.01$, respectively). In these areas, as seen in some of the areas described above, the lowest levels of Fos expression occurred between ZT 18 and ZT 22 (Fig. 4).

\subsection{Experiment 2: Putative projections to the CSF}

3.2.1. Retrograde tracing-Ten grass rats received injections that included the $3 \mathrm{~V}$ and/ or surrounding hypothalamic areas and 6 received injections that included the LV and/or the dorsal part of the lateral septal nucleus (LSd). Of these cases, one grass rat had an injection site that was centered in the ventricular system, specifically in the $3 \mathrm{~V}$ (Fig. 5). In the cases in which the injection sites extended from the $3 \mathrm{~V}$ into the periventricular hypothalamic region ( 8 cases), the pattern of labeled cells and processes was similar to that produced by the injection restricted to the $3 \mathrm{~V}$ including intense labeling in the DR (see below), but in addition, cellular labeling was present throughout the hypothalamus, lateral septum, and amygdala (data not shown). Injections that extended from the LV to the caudal LSd (5 cases) also produced intense cellular labeling in the DR, but in addition cellular labeling was found in the medial septum, vertical and horizontal diagonal bands of Broca, amygdala, hippocampus, thalamus and hypothalamus (data not shown). In contrast, when the injection site included neither the $3 \mathrm{~V}$ (only periventricular areas; 1 case), nor the LV (only the caudal LSd; 1 case, or cingulate cortex; 1 case), the cluster of CTB-labeled cells seen in the DR of all the other cases as well as the intense labeling of the surrounding ependyma were absent (Fig. 6A and 6B). The description that follows is based on the case restricted to the $3 \mathrm{~V}$ (Fig. $5)$.

The injection of CTB restricted to the $3 \mathrm{~V}$ (Fig. 5) produced intense labeling in the ependymal cell layer surrounding the lateral ventricles, $3 \mathrm{~V}$, cerebral aqueduct, and $4 \mathrm{~V}$. A dense cluster of labeled cells was observed in the caudal DR, specifically in the mDR3, and throughout the mDR4 and mDR5 (Fig. 6A). These labeled cells appeared first in the ventral part of the mDR3, and more caudally their distribution expanded into the dorsal part of the DR. Labeled processes that appeared to belong to these cells were observable clearly approaching the ependymal cell layer of the cerebral aqueduct and 4V (Fig. 6A). In contrast to the DR, only a few scattered labeled cells were present in the MR. Outside of the raphe nuclei there was intense labeling of tanycytes in the median eminence (ME; Fig. 6D) and scattered cell labeling in the hypothalamus, including the suprachiasmatic nucleus (SCN; 
Fig. 6C), ventral subparaventricular zone (vSPZ; Fig. 6C), ME (Fig. 6D), paraventricular nucleus of the hypothalamus (PVN; Fig. 6E), and the DTM (Fig. 6F).

3.2.2. CTB and 5HT double-labeling-According to our retrograde tracing results, the periventricular nucleus of the hypothalamus is not likely to receive afferent projections from the DR since an injection in this region that missed the $3 \mathrm{~V}$ did not produce CTB positive cells in the DR (see previous subsection). Therefore, to analyze CTB and 5HT doublelabeling we not only used the case in which the injection was restricted to the $3 \mathrm{~V}$, but also one case in which the injection site extended from the $3 \mathrm{~V}$ into the periventricular nucleus of the hypothalamus. In both cases, the distribution and abundance of CTB positive cells was similar in brain sections processed for light and fluorescent microscopy (Fig. 6A and Fig. 7C), with the rostro-caudal gradient of CTB positive cells extending from the caudal mDR3 to the end of the mDR5. Additionally, the number of double labeled cells (i.e., positive for both 5HT and CTB), was similar in the two cases. Between 67 to $80 \%$ of the retrogradelly labeled cells of the caudal mDR were immunopositive for 5HT, and between 25 to $30 \%$ of serotonergic cells were also immunopositive for CTB (Fig. 7B).

\section{Discussion}

\subsection{Fos expression in the DR and MR}

In nocturnal animals the release of 5HT from the raphe into its target areas, including the SCN, is increased during the active phase (Barassin et al., 2002), as is the case in the Sudanese grass rat, Arvicanthis ansorgei, a diurnal rodent closely related to our grass rat (Cuesta et al., 2008). Thus, the time of day at which the release occurs is reversed when diurnal and nocturnal rodents are compared. In our grass rats, we observed increased Fos expression during the active phase within serotonergic cells in some regions of the raphe but not others. Specifically, whereas 5HT cells in the caudal mDR showed a day-night difference in Fos expression, cells in the IDR, MR, and rostral areas of the MR did not. Since the pattern of Fos expression identified in the caudal mDR of our grass rat corresponds to the temporal pattern of 5HT release in the SCN of the diurnal Sudanese grass rat (Cuesta et al., 2008), it is likely that the circadian release of 5HT onto target areas including the grass rat SCN is mediated by terminals emanating from cells in the caudal $\mathrm{mDR}$. Topographic differences in Fos expression within the DR have also been identified in the crepuscular Mongolian gerbil, with Fos expression increasing during the transitions between lights on and off only in the caudal mDR; but the pattern is evident only in nonserotonergic cells (Janusonis and Fite, 2001). It remains to be determined whether these differences reflect underlying species differences or differences in their lifestyle habits. Additional evidence for functional differences in subdivisions of the DR comes from studies in which animals are exposed to stressful stimuli. For example, sleep deprivation induced by physical restraint in Syrian hamsters (Webb et al., 2010), and inescapable tail shock in rats (Grahn et al., 1999) elicit Fos expression selectively in serotonergic cells of the caudal DR. In contrast, social defeat paradigms in Syrian hamsters induce Fos expression in serotonergic as well as non-serotonergic cells in only the rostral DR (Cooper et al., 2009).

In addition to its role in promoting wakefulness, 5HT is involved in a variety of behavioral and physiological functions including aggression, sexual behavior, thermoregulation, dynamics of the CSF (Hung et al., 1993), and circadian rhythmicity (reviewed in Yannielli and Harrington, 2004), among others. Its latter role is of particular interest given that in nocturnal rodents, it modulates circadian responses to non-photic stimuli (i.e., phase shifts only during the subjective day; reviewed in Yannielli and Harrington, 2004), such as phase shifts of activity rhythms produced by social interactions or handling. Specifically, the DR and MR appear to mediate these effects via direct synaptic inputs to the SCN (MeyerBernstein and Morin, 1999). The non-photic phase shifts seen in nocturnal animals are in 
sharp contrast to the ones observed in the diurnal Sudanese grass rat. In this rodent, the effects of 5HT on the phase of activity rhythms are seen only during the subjective night (Cuesta et al., 2008). Thus, in diurnal and nocturnal species the effects of 5HT on the circadian pacemaker appear to be restricted to the rest phase of the species (Challet, 2007). The implications of these observations are important for understanding the differential role of $5 \mathrm{HT}$ in the circadian regulation of behavior in diurnal and nocturnal species.

We also observed a day-night difference in Fos expression in non-serotonergic cells that were restricted to some subpopulations of the raphe, namely the mDR4 and MR. Future work needs to investigate the chemical phenotype of these groups as non-serotonergic neurons from the DR and MR appear to directly interact with brain regions involved in important physiological and behavioral functions. For example, GABAergic neurons of the DR project to the prefrontal cortex, lateral hypothalamus, and nucleus accumbens; areas involved not only on physiological functions but also on cognition (Bang and Commons, 2012). Also, glutamatergic cells of the MR project to the hippocampus, an area involved in learning, memory and emotional regulation, and have been implicated in the regulation of hippocampal neural activity (Jackson et al., 2009). Thus, the day-night profile of Fos expression seen in non-serotonergic cells of the mDR4 and MR could be related to the roles that these brain areas have in the modulation of diverse brain processes throughout the sleep/ wake cycle.

\subsection{Fos expression in the TMM and SUM}

The TMM of several nocturnal species contains dense clusters of histaminergic neurons which show peak firing during wakefulness (Takahashi et al., 2006), as well as increase Fos expression at that time (Ko et al., 2003). Unfortunately, due to technical difficulties with the double-label ICC, in this study we could not determine specifically whether histaminergic cells of the TMM showed Fos expression patterns. We, however, were able to identify daynight difference in Fos expression in the VTM and DTM, with higher Fos production during the day than during the night. This pattern is similar to one reported earlier (Novak et al., 2000), although with only four sampling times, the previous study missed detecting a significant effect of time on Fos expression in the DTM. Of note, both the DTM and VTM of grass rats show a circadian pattern in the expression of the clock protein Per 1 (Nunez et al., 2012) suggesting that these areas may participate in the regulation of circadian rhythmicity in grass rats.

The SUM contains a variety of neuronal phenotypes, including neurons immunoreactive for dopamine, calretinin, substance P, vaso-intestinal peptide (reviewed in Pan and McNaughton, 2004), as well as for GABA and glutamate related markers (Soussi et al., 2010); these neurons project to brain areas that regulate behavioral state. In fact, the SUM, like the MR, plays a role in the modulation of the hippocampal theta wave, through indirect, as well as direct projections to the hippocampus (reviewed in Pan and McNaughton, 2004). In addition, the SUM plays a role in reward. Administration of excitatory glutamatergic agonists to the SUM induces conditioned place preference (Ikemoto et al., 2004), and exposure to rewarding stimuli elicits neural activation in this area (e.g., Marcangione and Rompre, 2008). Then, given that the SUM not only plays a role in the regulation of vigilance states, but also in reward, we expected to find a day-night difference in neural activity in this area. Our data confirmed that expectation; neurons of the SUM displayed a day-night profile in Fos expression, with the highest values in the transitions between lights on and off, and the lowest values in the mid-day and night. This Fos pattern is similar to the locomotor activity patterns that grass rats show in the laboratory under a 12:12 light-dark cycle (McElhinny et al., 1997). This concordance is interesting given that in lab rats chemical stimulation of this nucleus not only increases Fos expression in the SUM but also appears to facilitate locomotor activity (Shin and Ikemoto, 2010). Future work is needed to address the 
possibility that neural activity in the SUM could influence daily patterns of spontaneous locomotor activity in our grass rats.

\subsection{Putative projections to the CSF}

The CSF carries myriad molecules, including 5HT and HA, through the nervous system. In addition to playing a role in the promotion of wakefulness and in regulation of circadian rhythmicity, 5HT and HA have been linked to some behavioral disorders. For example, HA metabolites in the CSF are higher in schizophrenics than in healthy individuals (Prell et al., 1995), and in patients with major depression and a history of attempts to commit suicide 5HT in the CSF is lower than in non-suicidal patients (Hou et al., 2006). These phenomena are intriguing given that HA and 5HT are known to influence metabolism of the CP (Hung et al., 1993, Watson et al., 1995), where CSF is produced. The route by which these two neurotransmitters reach the CSF has not been definitively established but some evidence in the lab rat suggests that it is through direct release into the ventricles (5HT: Lorez and Richards, 1973, Chan-Palay, 1976, HA: Ericson et al., 1987). An additional source of 5HT and HA could be mast cells. This possibility remains to be tested, as these cells are known to synthesize both neurotransmitters (Hough, 1988, Kushnir-Sukhov et al., 2007) and to be located in the CP (Dropp, 1976). In this study, we addressed whether neurons of the raphe and TMM could release their contents rhythmically into the CSF. To this aim we determined if CTB injected into the $3 \mathrm{~V}$ and $\mathrm{LV}$ of grass rats would result in the retrograde labeling of neurons in regions of the brain known to not only contain histaminergic and serotonergic cell bodies, but also to display day-night differences in neural activity.

Taken together, our results from the case in which the injection site was restricted to the ventricular system in addition to the cases in which this system was partially included or missed, helped us corroborate the pattern of projections to the CSF. It is noteworthy that injections that hit the ventricular system at different sites in the rostro-caudal axis (i.e., LV and $3 \mathrm{~V}$ ) revealed a rather similar pattern of retrograde labeling. We found that after the injections to both the $3 \mathrm{~V}$ and $\mathrm{LV}$, the caudal $\mathrm{mDR}$ showed strong cell labeling whereas the TMM showed scarce cellular labeling restricted to the DTM. Furthermore, labeled fibers in the mDR and DTM were seen in close proximity to the $3 \mathrm{~V}$, which suggests that these cells could release their content directly into the CSF. These findings are in agreement with observations made in nocturnal lab rats (Mikkelsen et al., 1997, Simpson et al., 1998). In addition, injections to the $3 \mathrm{~V}$ and $\mathrm{LV}$ produced cell labeling in the SCN. This pattern of staining is interesting given that diffusible signals released from this nucleus have been proposed to control circadian rhythms in locomotor activity (Schwartz and Reppert, 1985, Lehman et al., 1987, Silver et al., 1996). Our results suggest that a potential route for this control is a direct one from the SCN to the CSF. We also observed a few labeled cells in the vSPZ, an area that appears to participate in circadian rhythmicity in the grass rat and in nocturnal rodents (Lu et al., 2001, Schwartz et al., 2009). Perhaps some of these cells in the vSPZ influence rhythms via release of signals into the CSF.

The majority of the retrogradely labeled neurons seen in the caudal DR were serotonergic. We found that approximately two thirds of the CTB labeled cells of the DR were positive for 5HT; a similar pattern has been identified in the nocturnal lab rat (Mikkelsen et al., 1997). Interestingly, the double-labeled cells identified in this study were found in the same areas where we detected a day-night difference in Fos expression in serotonergic cells. These observations hint that 5HT from the caudal DR may be released into the CSF in a rhythmic fashion. This is a likely scenario as putative serotonergic axons from the raphe have been identified in the supra-ependymal plexuses of all ventricles (Aghajanian and Gallager, 1975). Also, 5HT concentrations in the LV show a pattern of release that covaries with the ultradian bouts of REM and non-REM sleep (Zeitzer et al., 2002), sleep stages which are known to be modulated by $5 \mathrm{HT}$ neurons of the raphe. Serotonin, once in the CSF, 
could control $\mathrm{CP}$ functioning by acting on the $\mathrm{CP}$ serotonergic receptors located proximally or downstream of the release site. In the TMM and DR, we also observed retrogradely labeled cells of unknown chemical phenotype. Further work needs to address this question, especially because if these retrogradely labeled cells also show daily patterns of activation (as seen in the TMM and mDR4), they may be releasing their contents into the CSF in a rhythmic fashion.

\subsection{Conclusions}

In summary, this study shows that wake-promoting areas of a diurnal species display a reversal in neural activation when compared to nocturnal species. Given that the grass rat is a model used to study the effects of nocturnal shift work (Castillo-Ruiz et al., 2010, Ramanathan et al., 2010), our findings are informative as they provide normative, baseline information on Fos expression patterns in wake-promoting areas in this species. Together with previous work done in the wake-promoting orexinergic system of the grass rat (Martinez et al., 2002), our results provide further evidence that the evolution of diurnality required a complete reversal in the functioning of wake-promoting systems. It is likely that the increase in Fos expression in the raphe and TMM areas is associated with increased HA and 5HT release at synaptic terminals, as is the case for the wake-promoting system of the cholinergic basal forebrain (Greco et al., 1999, Greco et al., 2000). Therefore, the maximal effects of HA and 5HT in target areas, including the main pacemaker of the SCN, are likely to be seen during the active phase. The effects that the 5HT and HA may have on SCN functioning is a subject that warrants further investigation in diurnal species. Our anatomical results also indicate that chemical signals from the SCN and the vSPZ could be released directly into the CSF. This avenue for the control of circadian rhythms has been proposed before for nocturnal species (Schwartz and Reppert, 1985, Lehman et al., 1987, Silver et al., 1996). Our study is the first to provide evidence for that hypothesis in a diurnal mammal. Finally, our results may suggest that the release of 5HT from the raphe into the CSF may be involved in circadian control of various functions throughout the nervous system, which could include the production of CSF itself. Understanding of the functional complexity of the raphe nuclei is important, since changes in the physiology of this nucleus have been linked to severe human mental health problems including suicide (Boldrini et al., 2008).

\section{Acknowledgments}

We thank Cynthia Jordan, Sharleen Sakai, Lynwood Clemens, Lily Yan, Chidambaram Ramanathan, Adam Stowie, Toby Slater, Dorela Shuboni, Carmel Martin-Fairey, Steve Disler, and Anna Baumgras for their valuable technical assistance and/or comments on earlier versions of this paper. We also thank William J. Schwartz for his kind support of this project. This study was supported by the National Institute of Mental Health grant MH 53433. The content is solely the responsibility of the authors and does not necessarily represent the official views of the National Institutes of Mental Health.

\section{References}

Aghajanian GK, Gallager DW. Raphe origin of serotonergic nerves terminating in the cerebral ventricles. Brain Res. 1975; 88:221-231. [PubMed: 167906]

Bang SJ, Commons KG. Forebrain GABAergic projections from the dorsal raphe nucleus identified by using GAD67-GFP knock-in mice. J Comp Neurol. 2012; 520:4157-4167. [PubMed: 22605640]

Barassin S, Raison S, Saboureau M, Bienvenu C, Maitre M, Malan A, Pevet P. Circadian tryptophan hydroxylase levels and serotonin release in the suprachiasmatic nucleus of the rat. Eur J Neurosci. 2002; 15:833-840. [PubMed: 11906525]

Boldrini M, Underwood MD, Mann JJ, Arango V. Serotonin-1A autoreceptor binding in the dorsal raphe nucleus of depressed suicides. J Psychiat Res. 2008; 42:433-442. [PubMed: 17574270] 
Castillo-Ruiz A, Nixon JP, Smale L, Nunez AA. Neural activation in arousal and reward areas of the brain in day-active and night-active grass rats. Neuroscience. 2010; 165:337-349. [PubMed: 19837140]

Challet E. Minireview: Entrainment of the suprachiasmatic clockwork in diurnal and nocturnal mammals. Endocrinology. 2007; 148:5648-5655. [PubMed: 17901231]

Chan-Palay V. Serotonin axons in the supra- and subependymal plexuses and in the leptomeninges; their roles in local alterations of cerebrospinal fluid and vasomotor activity. Brain Res. 1976; 102:103-130. [PubMed: 813816]

Cooper MA, Grober MS, Nicholas CR, Huhman KL. Aggressive encounters alter the activation of serotonergic neurons and the expression of 5-HT1A mRNA in the hamster dorsal raphe nucleus. Neuroscience. 2009; 161:680-690. [PubMed: 19362123]

Crook RB, Farber MB, Prusiner SB. Hormones and neurotransmitters control cyclic AMP metabolism in choroid plexus epithelial cells. J Neurochem. 1984; 42:340-350. [PubMed: 6198461]

Crook RB, Farber MB, Prusiner SB. H2 histamine receptors on the epithelial cells of choroid plexus. J Neurochem. 1986; 46:489-493. [PubMed: 3001227]

Cuesta M, Mendoza J, Clesse D, Pevet P, Challet E. Serotonergic activation potentiates light resetting of the main circadian clock and alters clock gene expression in a diurnal rodent. Exp Neurol. 2008; 210:501-513. [PubMed: 18190911]

Dropp JJ. Mast cells in mammalian brain. Acta Anat (Basel). 1976; 94:1-21. [PubMed: 961335]

Ericson H, Watanabe T, Kohler C. Morphological analysis of the tuberomammillary nucleus in the rat brain: delineation of subgroups with antibody against L-histidine decarboxylase as a marker. J Comp Neurol. 1987; 263:1-24. [PubMed: 2822770]

Grahn RE, Will MJ, Hammack SE, Maswood S, McQueen MB, Watkins LR, Maier SF. Activation of serotonin-immunoreactive cells in the dorsal raphe nucleus in rats exposed to an uncontrollable stressor. Brain Res. 1999; 826:35-43. [PubMed: 10216194]

Greco MA, Lu J, Wagner D, Shiromani PJ. c-Fos expression in the cholinergic basal forebrain after enforced wakefulness and recovery sleep. Neuroreport. 2000; 11:437-440. [PubMed: 10718290]

Greco MA, McCarley RW, Shiromani PJ. Choline acetyltransferase expression during periods of behavioral activity and across natural sleep-wake states in the basal forebrain. Neuroscience. 1999; 93:1369-1374. [PubMed: 10501461]

Guzman-Marin R, Alam MN, Szymusiak R, Drucker-Colin R, Gong H, McGinty D. Discharge modulation of rat dorsal raphe neurons during sleep and waking: effects of preoptic/basal forebrain warming. Brain Res. 2000; 875:23-34. [PubMed: 10967295]

Harrington ME, Biello SM, Panula P. Effects of histamine on circadian rhythms and hibernation. Biol Rhythm Res. 2000; 31:374-390.

Hou C, Jia F, Liu Y, Li L. CSF serotonin, 5-hydroxyindolacetic acid and neuropeptide Y levels in severe major depressive disorder. Brain Res. 2006; 1095:154-158. [PubMed: 16713589]

Hough LB. Cellular localization and possible functions for brain histamine: recent progress. Prog Neurobiol. 1988; 30:469-505. [PubMed: 3287452]

Hung BC, Loo DD, Wright EM. Regulation of mouse choroid plexus apical Cl- and $\mathrm{K}+$ channels by serotonin. Brain Res. 1993; 617:285-295. [PubMed: 8402156]

Ikemoto S. Brain reward circuitry beyond the mesolimbic dopamine system: A neurobiological theory. Neurosci Biobehav Rev. 2010; 35:129-150. [PubMed: 20149820]

Ikemoto S, Witkin BM, Zangen A, Wise RA. Rewarding effects of AMPA administration into the supramammillary or posterior hypothalamic nuclei but not the ventral tegmental area. J Neurosci. 2004; 24:5758-5765. [PubMed: 15215298]

Jackson J, Bland BH, Antle MC. Nonserotonergic projection neurons in the midbrain raphe nuclei contain the vesicular glutamate transporter VGLUT3. Synapse. 2009; 63:31-41. [PubMed: 18925658]

Janusonis S, Fite KV. Diurnal variation of c-Fos expression in subdivisions of the dorsal raphe nucleus of the Mongolian gerbil (Meriones unguiculatus). J Comp Neurol. 2001; 440:31-42. [PubMed: 11745606] 
Janusonis S, Fite KV, Foote W. Topographic organization of serotonergic dorsal raphe neurons projecting to the superior colliculus in the Mongolian gerbil (Meriones unguiculatus). J Comp Neurol. 1999; 413:342-355. [PubMed: 10524343]

Jones BE. From waking to sleeping: neuronal and chemical substrates. Trends Pharmacol Sci. 2005; 26:578-586. [PubMed: 16183137]

Katona C, Smale L. Wheel-running rhythms in Arvicanthis niloticus. Physiol Behav. 1997; 61:365372. [PubMed: 9089754]

Ko EM, Estabrooke IV, McCarthy M, Scammell TE. Wake-related activity of tuberomammillary neurons in rats. Brain Res. 2003; 992:220-226. [PubMed: 14625060]

Kushnir-Sukhov NM, Brown JM, Wu Y, Kirshenbaum A, Metcalfe DD. Human mast cells are capable of serotonin synthesis and release. J Allergy Clin Immunol. 2007; 119:498-499. [PubMed: 17291861]

Lehman MN, Silver R, Gladstone WR, Kahn RM, Gibson M, Bittman EL. Circadian rhythmicity restored by neural transplant. Immunocytochemical characterization of the graft and its integration with the host brain. J Neurosci. 1987; 7:1626-1638. [PubMed: 3598638]

Lorez HP, Richards JG. Distribution of indolealkylamine nerve terminals in the ventricles of the rat brain. Z Zellforsch Mikrosk Anat. 1973; 144:511-522. [PubMed: 4276268]

Lu J, Zhang YH, Chou TC, Gaus SE, Elmquist JK, Shiromani P, Saper CB. Contrasting effects of ibotenate lesions of the paraventricular nucleus and subparaventricular zone on sleep-wake cycle and temperature regulation. J Neurosci. 2001; 21:4864-4874. [PubMed: 11425913]

Marcangione C, Rompre PP. Topographical Fos induction within the ventral midbrain and projection sites following self-stimulation of time posterior mesencephalon. Neuroscience. 2008; 154:12271241. [PubMed: 18556137]

Martinez GS, Smale L, Nunez AA. Diurnal and nocturnal rodents show rhythms in orexinergic neurons. Brain Res. 2002; 955:1-7. [PubMed: 12419515]

McElhinny TL, Smale L, Holekamp KE. Patterns of body temperature, activity, and reproductive behavior in a tropical murid rodent, Arvicanthis niloticus. Physiol Behav. 1997; 62:91-96. [PubMed: 9226347]

Meyer-Bernstein EL, Morin LP. Electrical stimulation of the median or dorsal raphe nuclei reduces light-induced FOS protein in the suprachiasmatic nucleus and causes circadian activity rhythm phase shifts. Neuroscience. 1999; 92:267-279. [PubMed: 10392849]

Mikkelsen JD, Hay-Schmidt A, Larsen PJ. Central innervation of the rat ependyma and subcommissural organ with special reference to ascending serotoninergic projections from the raphe nuclei. J Comp Neurol. 1997; 384:556-568. [PubMed: 9259489]

Novak CM, Smale L, Nunez AA. Rhythms in Fos expression in brain areas related to the sleep-wake cycle in the diurnal Arvicanthis niloticus. Am J Physiol Regul Integr Comp Physiol. 2000; 278:R1267-1274. [PubMed: 10801296]

Nunez, AA.; Groves, T.; Martin-Fairey, C.; Ramanathan, C.; Stowie, A.; Cramm, S.; Smale, L. The cost of nocturnal activity for a diurnal brain. Poster session presented at: Society for Neuroscience 42nd Annual Meeting; 2012 Oct 13-17; New Orleans, LA, USA.

Pan WX, McNaughton N. The supramammillary area: its organization, functions and relationship to the hippocampus. Prog Neurobiol. 2004; 74:127-166. [PubMed: 15556285]

Prell GD, Green JP, Kaufmann CA, Khandelwal JK, Morrishow AM, Kirch DG, Linnoila M, Wyatt RJ. Histamine metabolites in cerebrospinal fluid of patients with chronic schizophrenia: their relationships to levels of other aminergic transmitters and ratings of symptoms. Schizophr Res. 1995; 14:93-104. [PubMed: 7711000]

Ramanathan C, Stowie A, Smale L, Nunez AA. Phase preference for the display of activity is associated with the phase of extra-suprachiasmatic nucleus oscillators within and between species. Neuroscience. 2010; 170:758-772. [PubMed: 20682334]

Schwartz MD, Nunez AA, Smale L. Rhythmic cFos expression in the ventral subparaventricular zone influences general activity rhythms in the Nile grass rat, Arvicanthis niloticus. Chronobiol Int. 2009; 26:1290-1306. [PubMed: 19916832] 
Schwartz WJ, Reppert SM. Neural regulation of the circadian vasopressin rhythm in cerebrospinal fluid: a pre-eminent role for the suprachiasmatic nuclei. J Neurosci. 1985; 5:2771-2778. [PubMed: 4045552]

Shin R, Ikemoto S. Administration of the GABAA receptor antagonist picrotoxin into rat supramammillary nucleus induces c-Fos in reward-related brain structures. Supramammillary picrotoxin and c-Fos expression. BMC Neurosci. 2010; 11:101. [PubMed: 20716371]

Silver R, LeSauter J, Tresco PA, Lehman MN. A diffusible coupling signal from the transplanted suprachiasmatic nucleus controlling circadian locomotor rhythms. Nature. 1996; 382:810-813. [PubMed: 8752274]

Simpson KL, Fisher TM, Waterhouse BD, Lin RC. Projection patterns from the raphe nuclear complex to the ependymal wall of the ventricular system in the rat. J Comp Neurol. 1998; 399:61-72. [PubMed: 9725701]

Soussi R, Zhang N, Tahtakran S, Houser CR, Esclapez M. Heterogeneity of the supramammillaryhippocampal pathways: evidence for a unique GABAergic neurotransmitter phenotype and regional differences. Eur J Neurosci. 2010; 32:771-785. [PubMed: 20722723]

Takahashi K, Lin JS, Sakai K. Neuronal activity of histaminergic tuberomammillary neurons during wake-sleep states in the mouse. J Neurosci. 2006; 26:10292-10298. [PubMed: 17021184]

Tillet Y, Batailler M, Panula P. Histaminergic neurons in the sheep diencephalon. J Comp Neurol. 1998; 400:317-333. [PubMed: 9779938]

Watson JA, Elliott AC, Brown PD. Serotonin elevates intracellular $\mathrm{Ca} 2+$ in rat choroid plexus epithelial cells by acting on 5-HT2C receptors. Cell Calcium. 1995; 17:120-128. [PubMed: 7736561]

Webb IC, Patton DF, Landry GJ, Mistlberger RE. Circadian clock resetting by behavioral arousal: neural correlates in the midbrain raphe nuclei and locus coeruleus. Neuroscience. 2010; 166:739751. [PubMed: 20079808]

Wolburg H, Paulus W. Choroid plexus: biology and pathology. Acta Neuropathol. 2010; 119:75-88. [PubMed: 20033190]

Yannielli P, Harrington ME. Let there be "more" light: enhancement of light actions on the circadian system through non-photic pathways. Prog Neurobiol. 2004; 74:59-76. [PubMed: 15381317]

Zeitzer JM, Maidment NT, Behnke EJ, Ackerson LC, Fried I, Engel J Jr, Wilson CL. Ultradian sleepcycle variation of serotonin in the human lateral ventricle. Neurology. 2002; 59:1272-1274. [PubMed: 12391366]

\section{Abbreviations}

$\begin{array}{ll}\text { 3V } & \text { third ventricle } \\ \mathbf{4 V} & \text { fourth ventricle } \\ \mathbf{5 H T} & \text { serotonin } \\ \text { CP } & \text { choroid plexus } \\ \text { CSF } & \text { cerebrospinal fluid } \\ \text { CTB } & \text { cholera toxin subunit beta } \\ \text { DR } & \text { dorsal raphe } \\ \text { DTM } & \text { dorsal tuberomammillary nucleus } \\ \text { HA } & \text { histamine } \\ \text { ICC } & \text { immunocytochemistry } \\ \text { IDR } & \text { lateral dorsal raphe } \\ \text { LSd } & \text { lateral septal nucleus, dorsal part } \\ \text { LV } & \text { lateral ventricle }\end{array}$




$\begin{array}{ll}\text { mDR3-5 } & \text { medial dorsal raphe levels 3 through 5 } \\ \text { ME } & \text { median eminence } \\ \text { MR } & \text { median raphe } \\ \text { NDS } & \text { normal donkey serum } \\ \text { NGS } & \text { normal goat serum } \\ \text { PB } & \text { phosphate buffer } \\ \text { PBS } & \text { phosphate buffered saline } \\ \text { PLP } & \text { paraformaldehyde-lysine-sodium periodate } \\ \text { PVN } & \text { paraventricular nucleus of the hypothalamus } \\ \text { SCN } & \text { suprachiasmatic nucleus } \\ \text { SUM } & \text { supramammillary nucleus } \\ \text { TBS } & \text { tris buffered saline } \\ \text { TMM } & \text { tuberomammillary nucleus } \\ \text { TX } & \text { triton- } X \\ \text { vSPZ } & \text { ventral subparaventricular zone } \\ \text { VTM } & \text { ventral tuberomammillary nucleus } \\ \text { ZT } & \text { zeitgeber time }\end{array}$


Fos expression in brain sleep/wake areas predict a species temporal activity pattern Serotonergic neurons show daily rhythms of Fos expression in the diurnal grass rat Fos expression in the grass rat suprammamillary nucleus peaks at dusk and dawn Neurons of the grass rat tuberomammillary nuclei show rhythmic Fos expression Rhythmic serotonergic neurons of grass rats may have access to the ventricular system 

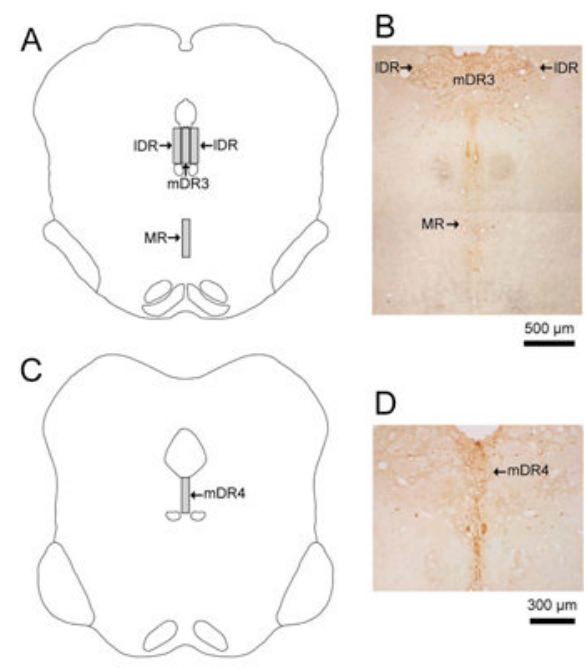

D

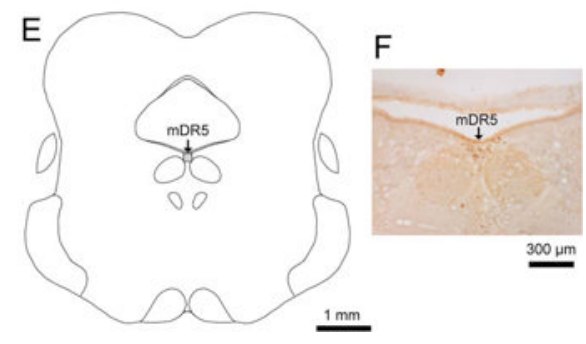

Figure 1.

Rostro-caudal illustrations and corresponding representative photomicrographs depicting the sampling regions used to quantify Fos expression in serotonergic and non-serotonergic cells of the IDR, MR, mDR3 (A, B), mDR4 (C, D), and mDR5 (E, F). See text for sampling box dimensions. Abbreviations: IDR, lateral dorsal raphe; mDR3-mDR5, medial dorsal raphe levels 3 through 5; MR, median raphe. 

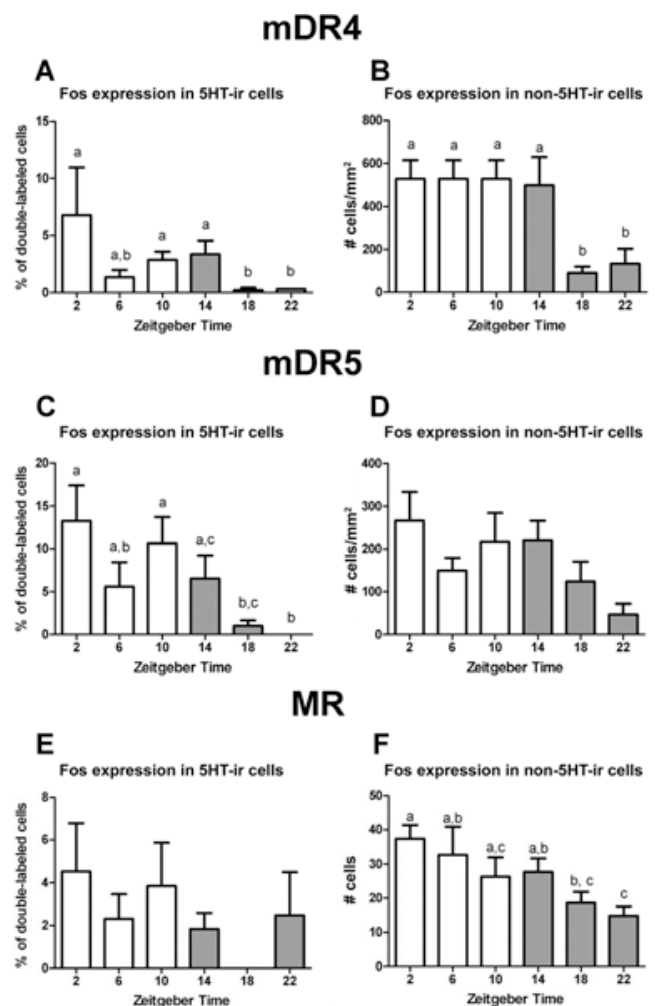

MR

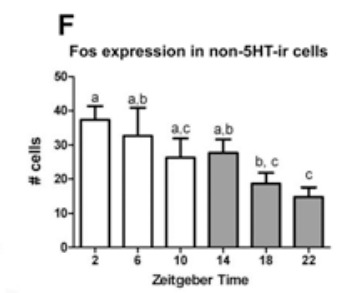

Figure 2.

Fos expression (mean \pm SEM) in serotonergic cells (A, C, and E) and non-serotonergic cells (B, D, and F) of the mDR4 (A and B), mDR5 (C and D), and MR (E and F) at six different zeitgeber times (white bars: light phase; grey bars: dark phase). Note that group means with different letters are significantly different from each other, here as well as in Figure 4.

Abbreviations: 5HT-ir, serotonin like immunoreactive; mDR4-mDR5, medial dorsal raphe levels 4 and 5; MR, median raphe. 

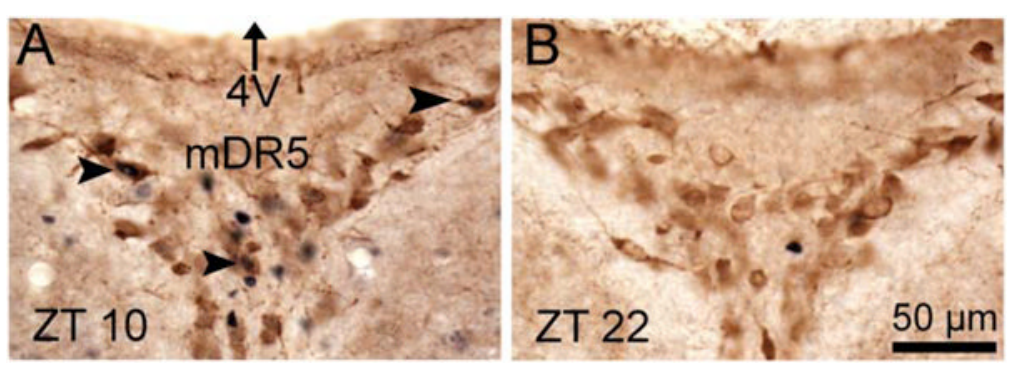

Figure 3.

Photomicrographs of serotonergic cells expressing Fos in the mDR5 at ZT 10 (A) and ZT 22 (B). Arrowheads indicate some double-labeled cells. Fos: blue nuclear staining. 5HT: brown cell body staining. Abbreviations: 4V, fourth ventricle; mDR5, medial dorsal raphe level 5; ZT, zeitgeber time. 

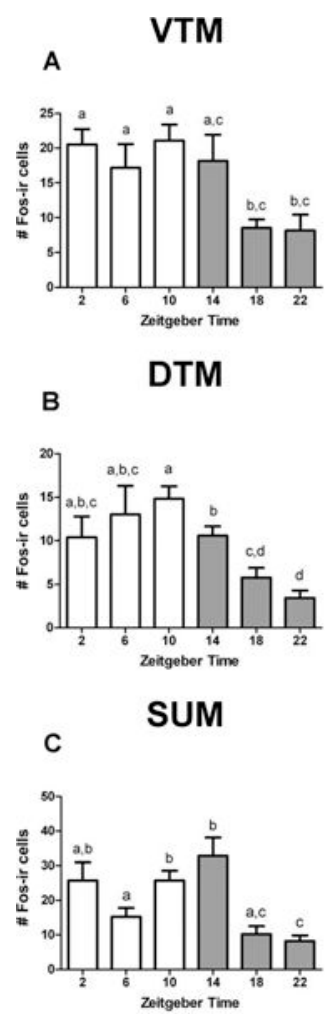

Figure 4.

Fos expression (mean \pm SEM) in the VTM (A), DTM (B), and SUM (C) at six different zeitgeber times (white bars: light phase; grey bars: dark phase). Abbreviations: DTM, dorsal tuberomammillary nucleus; Fos-ir, Fos like immunoreactive; SUM, supramammillary nucleus; VTM, ventral tuberomammillary nucleus. 


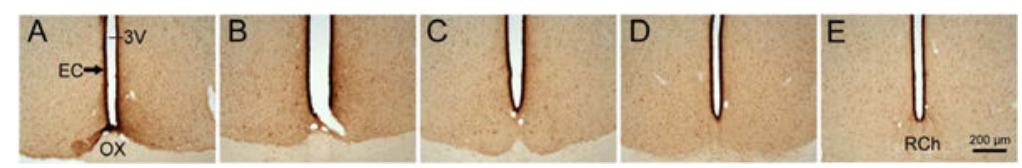

Figure 5.

Rostro-caudal photomicrographs of the CTB injection site in the $3 \mathrm{~V}$ (A-E). Abbreviations: $3 \mathrm{~V}$, third ventricle; CTB, cholera toxin subunit beta; EC, ependymal cell layer; OX, optic chiasm; RCh, retrochiasmatic area. 


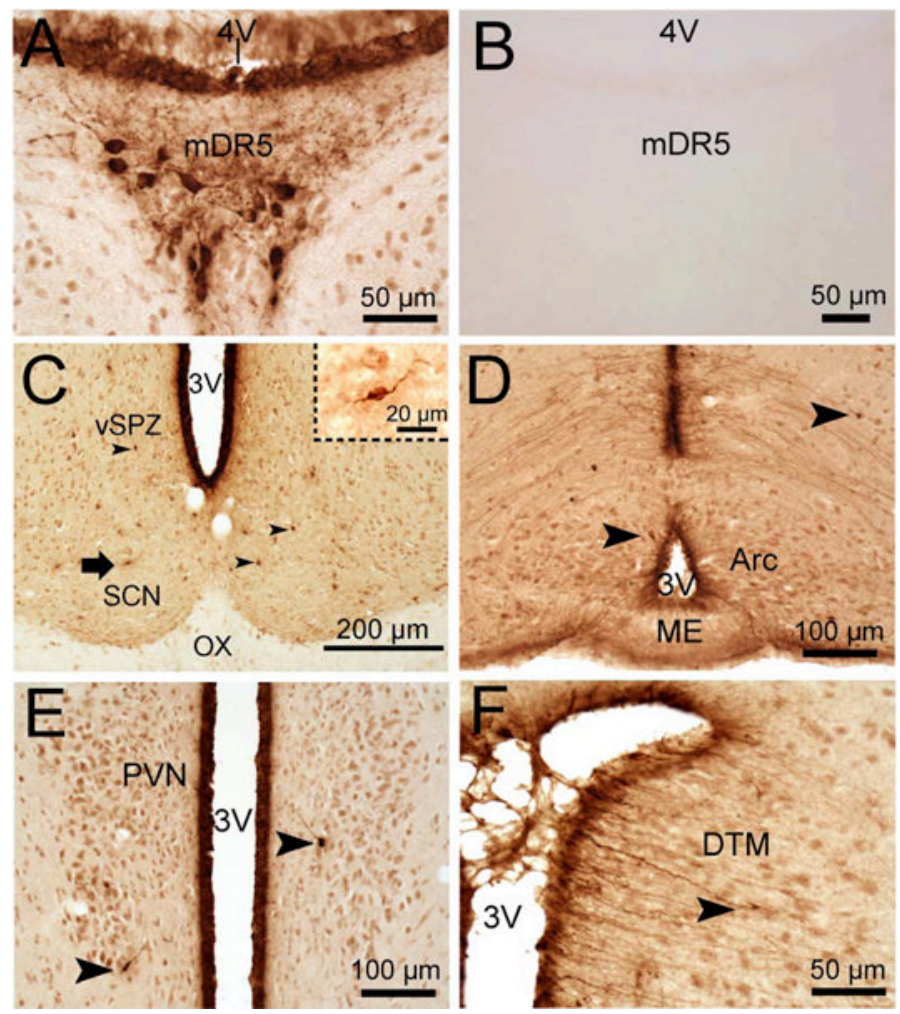

Figure 6.

Photomicrographs of areas that contained CTB-labeled cells after CTB injections to the ventricular system. Note the dense cell labeling in the mDR5 after injections to the ventricular system (A) in comparison to an injection that missed it (B). In addition, an injection restricted to the $3 \mathrm{~V}$ produced scattered cell labeling in the SCN and vSPZ [C, the arrow indicates a CTB-positive bipolar neuron magnified in the inset (upper right corner)], Arc (D), PVN (E), and DTM (F). Arrowheads indicate some CTB-labeled cells.

Abbreviations: $3 \mathrm{~V}$, third ventricle; $4 \mathrm{~V}$, fourth ventricle; Arc, arcuate nucleus; CTB, cholera toxin subunit beta; DTM, dorsal tuberomammillary nucleus; mDR5, medial dorsal raphe level 5; ME, median eminence; OX, optic chiasm; PVN, paraventricular nucleus of the hypothalamus; SCN, suprachiasmatic nucleus of the hypothalamus; vSPZ, ventral subparaventricular zone. 

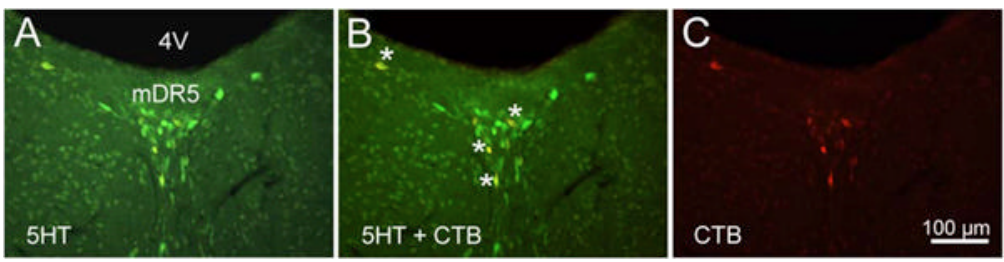

Figure 7.

Photomicrographs depicting cells in the mDR5 after staining with Cy2 labeled 5HT (A, green fluorescence) and $\mathrm{Cy} 3$ labeled $\mathrm{CTB}(\mathrm{C}$, red fluorescence) in a representative animal that received a CTB injection directed to the $3 \mathrm{~V}$. Panel B is a composite image showing both labels. White asterisks indicate some double-labeled cells. Abbreviations: 4V, fourth ventricle; CTB, cholera toxin subunit beta; mDR5, medial dorsal raphe level 5. 